\title{
future internet
}

ISSN 1999-5903

www.mdpi.com/journal/futureinternet

Article

\section{Social Empowerment of Intellectually Impaired through a Cloud Mobile System}

\section{Laura Freina ${ }^{1, *}$, Rosa Bottino ${ }^{1}$, Michela Ott $^{1}$ and Filippo Costa ${ }^{2}$}

1 CNR-ITD, Via de Marini 6, 16149 Genova, Italy; E-Mails: bottino@itd.cnr.it (R.B.); ott@itd.cnr.it (M.O.)

2 SoftJam S.p.A., Via Piave, 7, 16145 Genova, Italy; E-Mail: f.costa@softjam.it

* Author to whom correspondence should be addressed; E-Mail: freina@itd.cnr.it; Tel.: +39-010-6475-303; Fax: +39-010-6475-300.

Academic Editor: Jogesh K. Muppala

Received: 30 July 2015 / Accepted: 11 November 2015 / Published: 17 November 2015

\begin{abstract}
There is not a unique definition of "empowerment", nevertheless the idea that it involves, on the one hand, people having control over their own lives and, on the other, some social aspects seems to be a common characteristic. Most authors recognize three levels of empowerment: individual, group, and community level, which are interconnected and changes at one level influence the others. Enhancing individual competence and self-esteem has a direct effect on the control of one's own life and, in turn, on the social components of empowerment. In this paper we present Smart Angel, a project that aims at creating a network involving families, caregivers, experts, and tutors, as well as the final users and their friends, based on a mobile cloud system in support of both everyday living and urban mobility for people with medium-mild intellectual disabilities, with particular attention to the Down syndrome. The system can be seen as a tool to empower its users to be more independent and therefore increasing their possibility to have an active role in their life and an active participation to the community.
\end{abstract}

Keywords: empowerment; intellectual disabilities; mobility; cloud computing; technology enhanced learning; serious games; intellectual impairments 


\section{Introduction}

In literature, there is not a unique definition of "empowerment", nevertheless the idea that it involves, on the one hand, people having control over their own lives and, on the other, some social aspects seems to be a characteristic that is common to most authors. Among many others, here are some of the definitions that can be found in literature: a "multi-dimensional social process that helps people gain control over their own lives" [1]. “... empowerment was defined as processes whereby individuals achieve increasing control of various aspects of their lives and participate in the community with dignity" [2]. "Empowerment conveys both a psychological sense of personal control or influence and a concern with actual social influence, political power, and legal rights. It is a multilevel construct applicable to individual citizens as well as to organizations and neighbourhoods; it suggests the study of people in context" [3]. Maton and Salem [4] describe empowerment as a process of enabling individuals, through participation with others, to achieve their primary personal goals.

Since the concept of "empowerment" has been used in many different contexts, among which social science, psychology, economics, politics, etc., it has taken on a wide range of meanings [5]. According to Lord and Hutchison [2], three levels can be identified in the concept on "empowerment":

- Individual level, which, as reported by Bleumers et al. [6], is more linked to a psychological approach. It has been described by Zimmerman as a process of change that involves intrapersonal, interactional and behavioural components [7].

- Group level, which can be matched to the organizational empowerment as defined by Zimmerman, which involves equipping individuals to exert control in achieving organizational effectiveness in service delivery and policy development [8].

- Community level, which refers to processes of interaction between individuals and organizations to enhance community living, thereby effecting changes in a larger social system.

These levels of empowerment are intimately linked and changes that take place at one level have implications on the other levels. Furthermore, the interactions across these levels are culturally and contextually dependent. The processes of empowerment are likely to vary according to the community, organization or society where they happen [3]. Nevertheless, empowerment can never be reached in an isolated individualized manner but is always a community supported process where the individual level is prerequisite for the further social levels [9].

Cyril et al. [5] report several studies in which initiatives to achieve empowerment can lead to health-related outcomes in a range of social and cultural contexts. In particular, Laverack [10] in his review recognizes a link between empowerment and health outcomes. In the literature on community psychology, empowerment is seen to enhance individual competence and self-esteem, which, in turn, increase the perception of personal control and have a direct effect on improving health outcomes.

It is therefore important for the community to find ways to empower people to have a better control over their own lives. To reach this goal, being able to live as independently as possible is a pre requisite. Even if this is a straightforward goal for most people, those who have some sort of impairment have to overcome difficulties and sometimes can never reach a complete level of autonomy.

Chadwick [11] well defines in his introduction the concepts and the problems related to intellectual disabilities: a situation that often leads to social exclusion, increased vulnerability and reduced life opportunities. Chadwick focuses on the use of Internet as a tool for empowerment, even if he recognizes 
that there are several problems in its use for people with intellectual disabilities, going from a number of barriers due to software design to limited access to the physical devices and worries of the caregivers who tend to see more problems than benefits. Nevertheless, if its use is properly mediated and contextualized, Internet can provide opportunities, reduce social barriers, help developing and maintaining friendships, and increase a positive self-esteem [12].

There usually is a strong association between Internet and its World Wide Web component, described as a set of documents often connected by hyperlinks. However, Internet is and can be much more than just a system to access information and manage communication. It already offers a wide set of tools that are very valuable in everyday life. Just to give an example, the project UniSchoolLab [13] promoted remote access to science labs for primary and secondary schools through Internet-based services and mobile learning devices. As such, it can be defined as a tool to empower people by enabling them to do things that otherwise they could not do.

In this paper, we argue that Internet, and, in particular, cloud based technologies, offer the basis for the development of tools to empower people allowing for a more complete and satisfying personal and social life, especially for those who have difficulty due to intellectual disabilities. After introducing the Smart Angel project [14], the specific issues addressed will be presented and finally the developed solution will be described, as well as the first tests and its expected impact on the users' personal and social empowerment.

\section{The Smart Angel Project}

Smart Angel is a two-year project, funded by the Italian Liguria region through the "Programma Attuativo Regionale del Fondo Aree Sottoutilizzate della Regione Liguria 2007-2013 (PAR-FAS)". The project aims at supporting urban mobility and everyday life of people with medium-mild intellectual impairments, giving them the possibility to gain a better control over their own lives while, at the same time, reassuring caregivers. The project is carried out by a consortium involving associations of cognitive impaired, scientific partners as well as small and medium enterprises. Smart Angel aims at creating a network involving families, caregivers, experts and tutors, as well as the final users and their friends, built on a mobile cloud based system to support both everyday living and urban mobility of people with medium-mild intellectual disabilities, with particular attention to the Down syndrome. As such, the system can be seen as a tool to empower its users to be more independent and therefore increasing their possibility to have an active role in their life and an active participation to the community.

Using Smart Angel, people with intellectual disabilities are supported in their daily activities. For example, if going to swimming pool at a certain time of the day is planned in a user's agenda, the system will remind him when it is time to start getting ready, what items will be needed in the swimming bag, at what time he has to leave the house, etc. Furthermore, if the user stops along the way for a long time, a reminder will warn him that he might be late; or if he turns the wrong way the system will automatically send him a message telling him that the pool is the other way. However, the user is always free to make his own decisions and avoid following the system's suggestions. The tutor, in his remote position, will see the user's position all the time and can always decide to intervene if he feels that it is needed. The planning of the daily agenda, as well as all the geographical information about the pool's location and the way to get to it are configured by the tutor optionally with the final user himself. 
Smart Angel is based on the "learning from experience" approach, which, due to the characteristics of the target users, we believe is more effective than those based on abstract thinking and conceptualization are. As an example, the RECALL project [15] aims to combine location-based services with games based learning to promote route learning by means of rehearsing, reflecting and reinforcing the routes. The project having very similar aims is based on very different underlying theoretical principles. RECALL is aimed at people with various impairments (learning disabilities, sensory impairments, etc.) that are different or milder than those considered by Smart Angel, and it makes extensive use of maps while in our project maps are not used for the end users since they require conceptualization and abstraction abilities.

In Italy, the project "Casa Più" [16] is a project that has some similarities with Smart Angel, aiming at the same target audience of intellectually disabled people, and it addresses very well everyday living support within the house, but it is not so supportive with respect to town mobility.

The Smart Angel system is based on an experimented didactic approach that the user association involved in the project (CEPIM: Centro Italiano Persone Down ONLUS, a non profit social organization for people with the Down syndrome) has traditionally been using for decades. Smart Angel has the objective to support the tutor's work by minimizing the need of personal intervention, which is of extreme importance due to the costs and the limited number of available tutors.

\subsection{Overall Description of the Smart Angel System}

In Figure 1, the main components of the Smart Angel platform are outlined: a set of Serious Games to support the development of basic skills, a monitoring system for the tutors and a set of apps developed for Smart Phones. A central cloud based platform collects all the users' data and connects the other elements of the system.

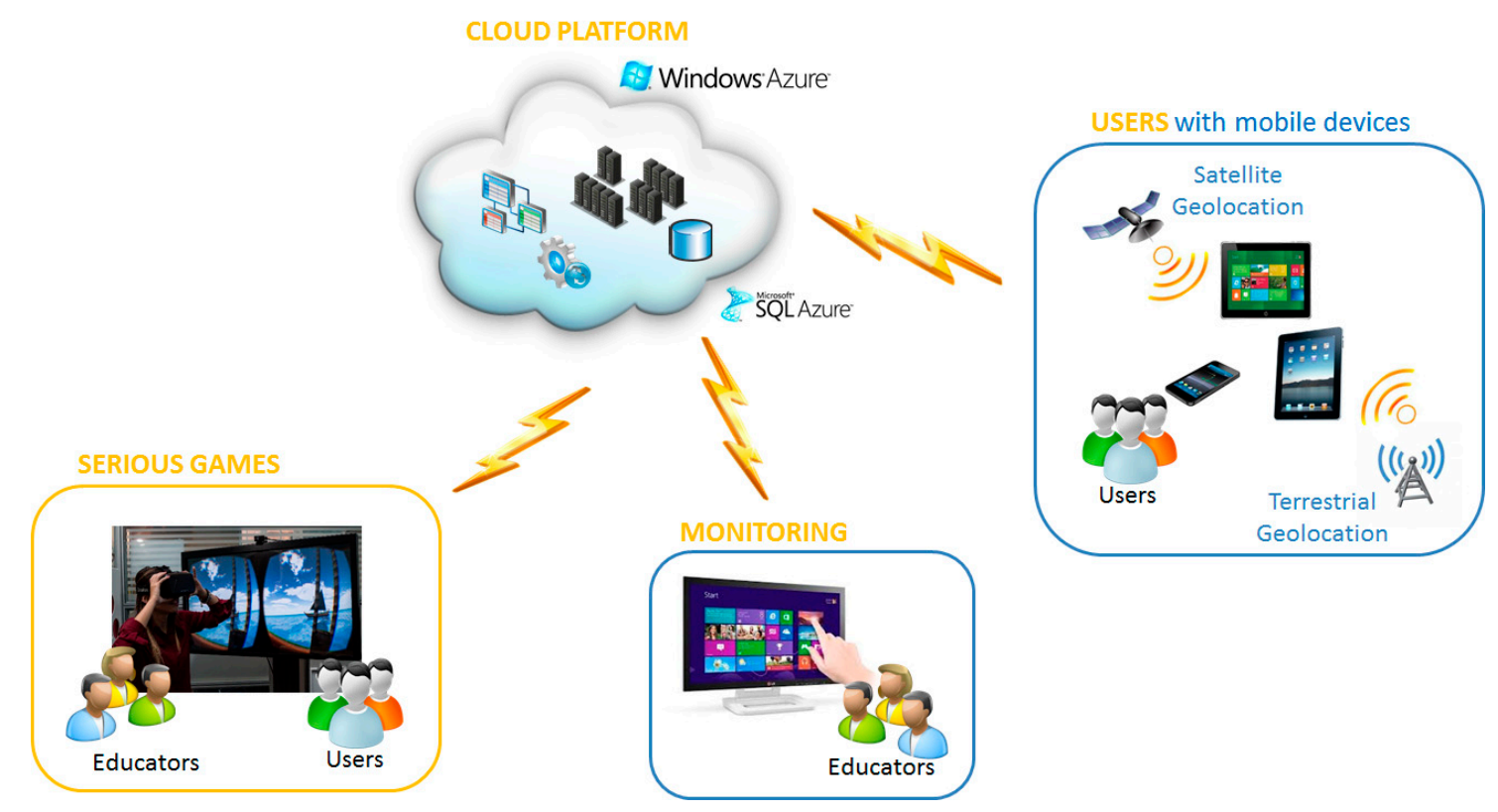

Figure 1. Smart Angel main components.

The games, based on an immersive virtual reality approach, aim at supporting and stimulating the development of some basic skills needed for independent mobility in town, and are used in the first steps towards independence. All the games exchange data with the central cloud system to guarantee 
uniqueness of the user profile and store all the performance data for later use. Nevertheless, they can be used on a standalone computer and automatically synchronize as soon as the connection becomes available.

When the users start being more independent, the monitoring system becomes a sort of guardian angel, standing by its user and offering help and support when needed without being intrusive. The mobile devices constantly exchange data with the cloud system: storing usage information, retrieving all the needed data and keeping both the tutor and the final user updated. The monitoring system, used by the tutors, allows having real time information on all the end users, configuring the users' systems and analysing the usage data collected in the cloud system.

The intellectually disabled people involved in Smart Angel have played a central role in all the different phases of the project. They have been actively involved right from the beginning in the user needs collection and analysis. In particular, a collaborative and participatory process has been carried out [17], involving a continuous and intensive dialogue among all the stakeholders (tutors, end users, developers, researchers).

Based on the user requirements, first prototypes of the Serious Games and the monitoring system have been developed and an initial experimental phase has started with a continuous feedback loop in order to reflect the real needs of the target users on all the stages of the project.

\subsection{Analysis of the User Needs}

A user requirements analysis has been organized with the aim of focusing the specific problems the target users have to face every day and that can be supported by the Smart Angel system. Information has been collected mainly through interviews and direct observation involving both tutors and the target users from the user association partner in the project, CEPIM.

All the interviews with the tutors were aimed at identifying the most important areas of weakness that the people they were following had to face in everyday life. Several meetings have been organized in the first four months of the project involving the tutors in charge of three different age groups:

- Teenagers (14-18), who still attend school and do not yet have much autonomy, but are getting ready for it, they are learning orientation, use of money, specific routes in town to reach school, etc.

- Young adults beginning an independent life (age 18-30). They are usually able to move independently, they can have a job and manage several leisure time activities by themselves. They cannot live completely on their own since they need caregivers support in some daily activities, for example, when handling money is involved, when they need to do some computations (e.g., computing food quantities based on the number of eaters), or for potentially dangerous activities (e.g., hanging cloths to dry outside the window).

- Adults who are already settled in their daily routine, which, usually, involves a certain degree of independence.

During the requirement analysis collection, the target users have been personally involved through meetings and direct observation.

Four young people with the Down syndrome between the age of 18 and 19 have been interviewed with the presence of their tutors. All of them were either finishing school or had just started a new job. 
They had different levels of autonomy: while two of them had a job, moved independently, performed little house works, etc., the other two were still very dependent on their families. During the interview, each one of them told us how they lived, what their job was, how they reached their job, if they went out with friends, etc.

A visit has been paid, for a whole afternoon, to a group of four young men (between 25 and 30) who were temporarily living in a supervised apartment. As part of their path towards independence, the user association organized periods of two weeks during which the four people with disability lived in the apartment, alternating with two weeks at home with their families. While living in the apartment, a caregiver was always present and helped the group to get organized; together they defined rules and a weekly planning of the housework where each person had his own responsibility. Specific routines and daily habits were created in order to help them organize their life at home. The four people all worked and were able to get the train and bus to go to work and come back home by themselves.

While we were visiting them, they started the sequence of activities needed to prepare dinner. The menu had already been decided, two people were in charge of the shopping list: one checked what was already in the house and the other wrote the list. The caregiver was always present and active, he decided when it was time to write the list, helped them to compute the amount of food needed and told them when to go shopping. We went with them to the shops, where they were completely independent and mastered the needed activities as expected by their tutor.

The analysis of the user needs identified several fields in which help was needed. Within the project, we decided to address two specific issues that had been recognized as general and recurring problems: urban mobility and time management.

\subsection{Smart Angel Typical User}

Following the user requirement analysis, the project defined the typical Smart Angel user focusing on the group of teenagers and the one of young adults. Some general characteristics common to most of the target users have been identified.

Most of the people belonging to the target groups have and normally use a personal Smart Phone, use computers, play games, etc. In general, they have a positive attitude towards Information and Communication Technology (ICT), and have the basic skills to use it, mainly for playing activities. We decided that there was no need for a technical training on the use of Smart Phones or computers.

Most of the people we considered tended to like routines, they preferred to repeat previous choices rather than make completely new ones. They usually had a small set of activities they mastered and freely chose to do them in their free time.

Special care was taken in the design of the interface of all the system components for three different reasons. First of all not all the end users can read, therefore all the communications from the system to the user can be read by a synthetic voice or represented by icons. The used icons can be chosen by the end user, together with his tutor, so that their meaning is clear and it will later be understood. Secondly, some users had problems in fine motor control; therefore, they found it difficult to focalize on a small object on a screen. The interface has to be simple, with few commands on each screen and clear enough to be seen correctly. Finally, the cognitive problems most users have can make it very difficult to understand complex messages. 


\subsection{Smart Angel and Time Management}

One of the two areas that we decided to address was time management. The typical user can read correctly the time on a clock and can usually say if a certain time has passed or if it is still in the future. What is difficult to manage is the time span needed to perform daily actions and routines. They need some help in deciding when it is time to start an action. For example, if a person has to be at the gym at 5 p.m., he will have to start packing the bag at 4:15 p.m. and leave home at 4:30 p.m.

Smart Angel provides a daily agenda, in which the daily routines and activities are defined by the caregiver, often involving directly the end user. The daily program can then be modified by the end user within some constraints. For example, while the time for work is fixed, shopping can be done at any time, as long as the shop are opened. The agenda can be completely personalized according to the users' needs, with respect both to the interface and to the reminders, which have to be efficient but not too intrusive.

During the day, the system will then automatically remind the user when it is time to start a certain activity. Multiple reminders are also possible, for example, the agenda can have a first reminder $15 \mathrm{~min}$ before an activity has to start and a second one five minutes before.

For some important activities, the agenda will ask the users to confirm that they have actually done it by a specific time, for example, it is important that the shopping is done before the shops close, and the activity has to be remembered otherwise it will be impossible to organize the dinner.

Time management has an impact also on mobility. Based on the current position in town, specific reminders may be needed, for example to help the person get to work on time in case he stops on the way for any reason. Moreover, according to the user's current position and to the estimated time needed to get back home, the system may remind its user when it is time to start on the way back.

Furthermore, people with the Down syndrome, sometimes isolate themselves and become unaware of the world around them and of time going by. In these cases, a gentle reminder to help them get back on track may be very useful.

The Smart Angel agenda is aimed at supporting autonomous living, it can be a valid tool not only for those people who live a mostly independent life, but also for those who occasionally have to stay for some time alone at home, even if they are living with their own families. They may have to manage some small activity, as getting ready for the gym, and the specific support for time management is very useful. Furthermore, for all those who move independently to reach, for example, their place of work, the agenda will help them not to be late.

For the group of people living together, as for those we interviewed during the user requirement collection, a common planning can be done by the whole group with the help of the caregivers. The single activities will then be assigned to specific people who will be in charge of doing them and they will automatically fill up their personal agenda.

A centralized cloud based system stores all the users' data and all the information on the use of the system for later use. 


\subsection{Smart Angel and Urban Mobility}

Supporting urban mobility was the other main goal in the Smart Angel project. With respect to this issue, two main blocks of the system have been developed: a set of Serious Games supporting the development of basic skills and a monitoring system in support of urban mobility.

\subsubsection{The Serious Games}

Having in mind the group of teenager users, Smart Angel has developed three Serious Games in a visually immersive virtual environment with the aim of supporting the development of some basic skills and abilities useful for urban mobility.

The first serious game aims at exercising road crossing and awareness of street dangers [18]. The second presents the words "left", "right", and "straight", as well as the concepts linked to them, in order to be able to understand and follow simple road directions. The last game stimulates the development and consolidation of the spatial perspective taking skill. Two different versions of this game have been developed: one in a desktop based virtual reality [19] and the second one in a visually immersive virtual world [20].

Since many people with intellectual disabilities have difficulties in generalizing the concepts they have learned in a specific environment to a different one, in the Smart Angel project we have decided to implement all the Serious Games in an immersive virtual environment, which looks like the real world. Virtual environments are supposed to be more effective than other approaches with respect to the acquisition of several abilities. This is because the brain recognizes the virtual world as real and this facilitates the transfer of the learned skills to the real world [21], that is the ability to apply acquired knowledge or skills in different situations or environments.

All the games are developed to be played by the target users in the presence of a tutor. The tutors pay attention to limiting the play sessions to less than 10 minutes each, alternating them with small breaks in order not to tire the users too much and maximize learning performance. Nevertheless, all the games can be used independently by a single player. The first tests are now carried out at the day care centre, but it is foreseen that games will also be used at home with the help of caregivers or family members.

\subsubsection{The Monitoring System}

In addition to the games, a monitoring system has been developed to support those users who already have the ability to move independently in known areas of their own town. Even if they usually move without any problem, some specific issues needed to be addressed.

In particular, unplanned situations, which may arise in everyday life, cause concern in the users. A strike of the public transport may cause a complete change in the "going to work" routine, missing a bus stop needs re-planning of one's walking route to go back on track, a road closed for street works may make an area inaccessible, etc. In all these cases, the monitoring system works in two ways. On the one hand, when the user leaves the area of town that he knows, the system signals the tutor that there is a possible problem and the tutor can then decide if intervention is needed. On the other hand, the system gives the user some immediate help by telling him where he is, suggesting alternative routes or simply 
offering him to ask for help to the tutor in charge. The use of standard maps is not possible for most people with intellectual disabilities since it requires a high level of abstraction, which can rarely be reached, therefore a specific system was needed by the target users.

Furthermore, those people who, in the past, got lost for any reason may have fear of it happening again. Often just knowing that there is a system through which they get immediate support, so that they do not feel alone, is of basic importance: they can always ask the system if they are on the correct way, send a message to the tutor or get in touch directly with him.

Finally, as previously reported, time management can be an issue. The monitoring system takes care of checking that the person is on time according to his appointments, and provides reminders when needed. Automatically a notice can be sent to the tutor when the user gets to his destination.

Each end user has one or more safe areas, which are the areas in town that he knows well and in which he can move around with no problem. These areas are defined by the tutors who deeply know each person's abilities. The monitoring system alerts the tutor each time the user goes out of his safe areas, the tutor can then decide whether to intervene or not.

The availability of a system on which to rely in case of need stimulates the user to increase his independence, explore new areas and try new activities. He feels supported and knows that in case of need help can be requested and will be given. Privacy issues and informed consent have been taken into account and the involved user associations are active in addressing these themes.

\subsubsection{The Cloud-Based Component}

As defined by the National Institute of Standards and Technology, "Cloud computing is a model for enabling ubiquitous, convenient, on-demand network access to a shared pool of configurable computing resources (e.g., networks, servers, storage, applications, and services) that can be rapidly provisioned and released with minimal management effort or service provider interaction" [22]. Such an approach has the advantage of offering its users the possibility to concentrate on their own applications without having to consider the management of the hardware, the development of specific software services, scalability issues, etc.

In the Smart Angel project, the cloud system, based on Microsoft Azure, collects all the data coming from the tutors, the games and the monitoring activities and stores them in a central database developed with an SQL server and then deployed in cloud. From the end users' point of view, the cloud system allows connecting through a different smart phone and finding all previous data, as well as accessing the system from any place and at any time. The tutors can monitor their end users without having to be physically at the care centre. Furthermore, all the system related documents, photos and videos also are collected in the cloud database and managed by the cloud providers with respect to data security, backups, needed storage space, etc.

The cloud system offers several other advantages, the most important of which is its scalability. The system can easily grow with respect to the amount of data that can be handled and to the number of users (impaired people, tutors and associations). Within the project, the test is taking place with a limited number of users, but we already have contacts for an international follow-up involving different countries and when the prototype will become a product its users will grow. Furthermore, the system has the potentiality to be used also by different populations with similar problems as, for example, people at the first stages of dementia [23]. Moreover, tutors could ask for more or different usage data to be 
tracked and analysed. Therefore, both the quantity of data to handle and the needed data processing capability may have to grow considerably. A dedicated Internet server might perform well enough in the first experimental phases, but as the system grows, a great investment would be needed. The cloud solution allows to scale efficiently simply by changing a few software parameters.

Another important advantage of the cloud solution is that it offers business intelligence and machine learning algorithms. The cloud-based system allows analysing data in real time, also when complex analyses are needed and therefore it offers the best possible support both for the end users and for the tutors. For example, if a user leaves his safe area on a Tuesday morning, the system will immediately analyse the user's history finding out that in the last months he has gone out of the safe area in the same direction every Tuesday morning and the tutor has accepted the event as normal. The system will learn from previous data in real time, and will not alert then tutor for the same event again. Having a virtually unlimited computing power makes it possible to find answers to complex situations in a very short time.

Tracking algorithms are based on maps from the cloud provider, which are guaranteed to be up to date with respect to roads, public transports, pedestrian areas, etc. Furthermore, the cloud-based service offers data streaming management, which has been used for the tutors training sessions. Cloud services also guarantee that Smart Angel will be available $24 \mathrm{~h}$ a day and 7 days a week and all the involved servers will be upgraded when needed. This is a very important point since Smart Angel, in order to be efficiently used, needs to be accessible to the final users at any time. Having all these services available makes it possible to concentrate the project resources on the development and test of the specific prototype.

A close cooperation between research centres and Small Medium Enterprises (SMEs) characterizes the project. The involved SMEs are interested in the outcomes of the research project with the aim of making a product from the developed prototypes. The use of a commercially available cloud based platform is a good starting point for the product-engineering phase, supporting the transition of the prototype into a market product.

On the other hand, the use of the cloud-based system has opened some well-known issues, in particular the security of personal data, which is of extreme importance for us because of the target users we want to address. Data access has to be managed with special care since the system deals with sensitive data (e.g., information of the user's disability and skills). All sensitive data is managed separately from usage and performance data and all databases are encrypted.

\subsection{The Caregivers' Point of View}

The Smart Angel system foresees a situation in which the person with intellectual disability is followed by a caregiver or tutor who helps and monitors the person's everyday life. Often caregivers tend to limit the person's freedom because they foresee more problems than advantages. They are worried that the person may get lost or have any trouble and therefore do not let him move independently. Furthermore, they feel the responsibility that if anything bad should happen it would be their fault.

Having the possibility to use a monitoring system, will reassure the caregivers and the families who will be able to know the position of the person at any time, get in touch with him as needed, and receive an immediate help request if anything should go wrong.

Furthermore, the availability of a large set of data to be analysed from everyday monitoring activities allows having a better insight of the person's real level of independence. It often happens that the final 
user actually knows wider areas in town and that he is able to move around much more than what their caregivers think. Therefore, the level of independence that is given to each end user can be tailored to his real skills, making it higher if possible or, on the other hand, planning for specific intervention in case specific recurring problems should arise. Any deviation from standard can also be traced, which is important because it may be a sign that some kind of problem has arisen and correcting actions may be needed.

Caregivers can access the data in the cloud system and all its functions from any place via Internet; therefore, their presence is not linked to their being physically in the caring centre. Furthermore, outside official monitoring hours, family members may be involved in monitoring and support activities.

Finally, since data is continuously tracked by the system, the central database will become an informative resource to allow the health professionals to have a deeper knowledge of each single person on the one side and, on the other, to have statistical information about the disabilities. This will enable the social group to give better help by having a deeper understanding of the problems people with intellectual disabilities have to face and therefore giving them the tools needed to be as socially active as possible.

\section{The Smart Angel Tests}

The first tests have been organized according to a case study approach making reference to the tutors and end-users from CEPIM association. The typical Smart Angel users can have very different levels of independence as well as different abilities and skills. Some of them show a very good ability in moving around, avoiding getting lost and managing well nearly the whole town, while others have difficulty in learning one single path from home to school/work and have serious difficulty as soon as an unplanned situation arises. Moreover, as previously stated, Smart Angel is meant to be a tool for the tutors, therefore the way it is used will depend highly on the single tutor's approach. These characteristics make a quantitative evaluation hard to be carried out without a very high number of users, tutors and associations.

A case study approach is, according to the Smart Angel team, the best method for a first experimental phase of a complex system designed for these target users in order to be able, in a rather short time, to collect the needed information to calibrate the system.

The experimental part of the project is now being carried out according to the schema outlined in Figure 2. Since Smart Angel is a learning tool to support the person's path towards personal independence, we are not planning to test it with those disabled people who have already reached their full potential with respect to mobility and independent living.

The tests have been divided into three parts:

- Functional test, aiming at the usability of the system, verifying that the system is in line with the needs of the tutors and the end users, etc.

- Preparation phase, aiming at the test of the Serious Games.

- Increasing personal independence phase, which is centred on the mobile apps in support of both independent living and urban mobility. 


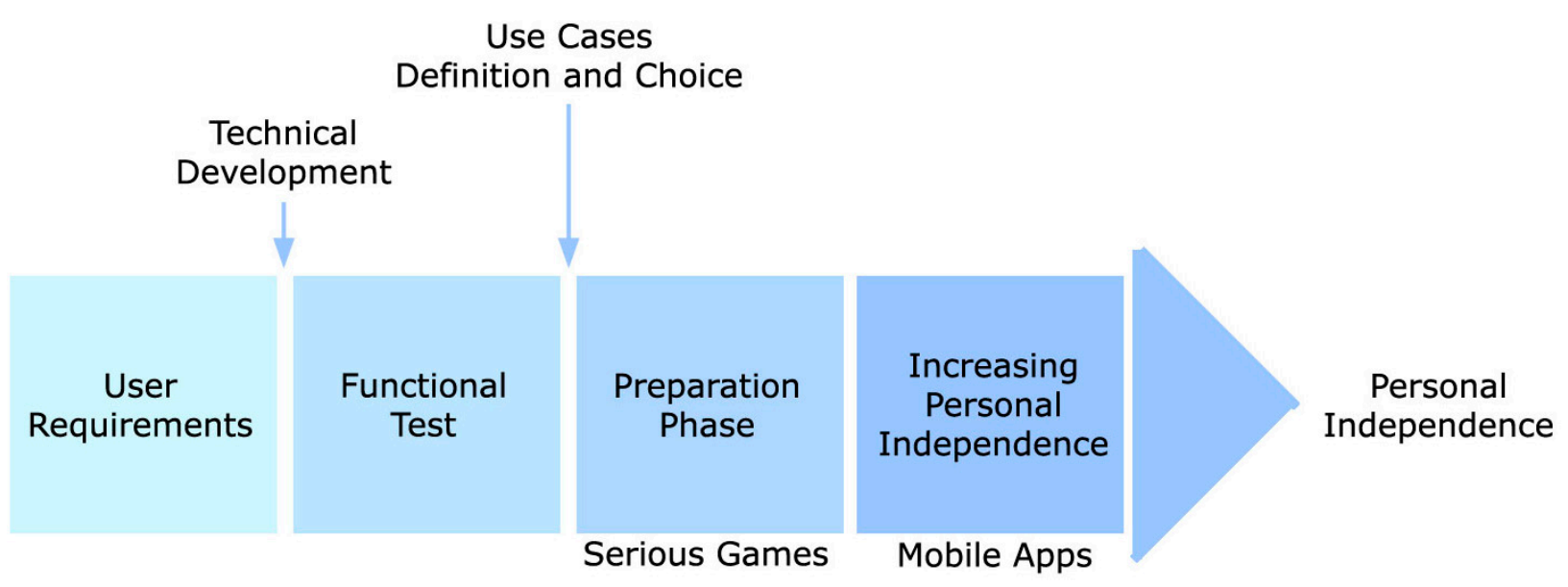

Figure 2. Smart Angel: planning of the tests.

At the moment, the functional test has finished and the preparation phase is well on the way since one of the two groups that are planned has finished it. The last test phase is planned to start soon with those users who have finished the preparation phase before the summer holidays. In the following chapters a deeper description of the first two tests is given.

\subsection{Functional Test}

After the user requirements collection, the first prototype has been developed and then its functionalities have been thoroughly tested by the tutors. Three tutors have been involved ever since the beginning of the project and now there are eight tutors performing the tests. All the tutors have used, for a four months period, the whole system, both with respect to the end user apps on the smart phones and the cloud based monitoring system. During this period, the group of developers met with the tutors at least twice a month and all their observations and comments have been collected. A continuous exchange of data is guaranteed by emails, some generated by the system as alerts and others sent by the tutors.

Some "errors" have been corrected, for example, when a tutor was being monitored on the border of a safe zone, the system was continuously sending alert messages saying that he was leaving the zone. A time limit has been added so that the same alert cannot be sent before some time has passed from the previous one. The system has been adapted to the tutors' comments; for example, it is now easier to create a new safe area by drawing it directly on the map and the accessibility of some functionalities has been made better. At the same time, the end user functionalities have been better calibrated and the interface revised in order to make it as simple as possible.

During these tests, a list of suggestions has been collected and it will be implemented in a future release of the system. For example, the possibility to have a "danger zone", an area of town that is particularly dangerous and has to be avoided at least in certain hours, as can be some parts of town during the night.

\subsection{Preparation Phase}

Seven young people between the age of 16 and 18 have then been identified for the first tests with the final users. They are about to start their adult life and are acquiring their independence. These people are undergoing a preparation phase, in which they are developing the basic skills needed for later 
independence. The Serious Games have been used as a tool to support the acquisition of some basic skills, but not all the involved users did actually take advantage from them: two of them had difficulty with the virtual reality head set and either had sickness or refused to use it. Nevertheless, the other users have shown a deep interest in the games, have used them a lot and have shown to get better in their performance.

The data collected from the test has already been used to better configure the games making the user interaction easier. The mechanism used to get the users' forward motion had to be calibrated in order to filter small movements and recognize intentional movements only. Some orientation problems are always felt when the headset is taken off. In order to help the player not to feel lost in space, the game always takes place in small area, which is limited by tables on which the player can hold in order not to lose his balance.

Data collected from the very first tests with two Serious Games is represented in Figure 3. The two games that had been tested at that point were related to the ability to safely cross the road and to understanding simple road directions. Both games are organized in "missions", which are made of one or more "tasks". Therefore, for example, a mission could be "reach the church" and it is made of the following three tasks: "turn right", "go to the end of the road and turn left", "go straight at the traffic light".

Each game session has always taken place with the tutors, who know the involved end users personally and deeply so they can understand the end users' reactions. Since the users were willing to play the games, but they tended to get over excited after a certain time of play, the tutors decided when it was time to end each play session.

The game automatically collected usage data that was then analysed separately. In particular, we considered the average time needed to complete the given tasks, the length of the whole session and the number of tasks completed.

In the analysis we found that two people have data that was much different from all the others, they had longer answer times and completed fewer tasks. In particular, user 6 refused to use the headset because he was very uncomfortable, he only played very few tasks and then wanted to end the play session. He did not participate in the following sessions. User 2 was at ease during the first session and performed well, while in the second play session she felt sick and had to leave the virtual world almost immediately.

After taking these two users out, we analysed the collected data with respect to the average duration of the sessions and the number of completed missions. This has been very useful because it gave us the needed information to write the guidelines for play. In particular, we found that sessions had to be kept short, we suggest no more than 5 to $8 \mathrm{~min}$. Furthermore, the number of scenes that have actually been played gave us useful information with respect to the needed global number of available missions to complete.

A deeper analysis of all the game related collected data will be performed shortly. The tests have been interrupted due to the summer holidays and therefore the lack of availability of the end users. In October, the tests have been resumed and another group of people is now involved in using the games. 
Overall data from all the sessions and all the users:

\begin{tabular}{|l|c|c|}
\hline & Min & Max \\
\hline Session length (minutes) & 2,43 & 10,11 \\
\hline Task (seconds) & 12,21 & 48,68 \\
\hline Mission (seconds) & 14,65 & 73,03 \\
\hline Number of missions & 2 & 19 \\
\hline Number of Tasks & 3 & 24 \\
\hline
\end{tabular}

Data from the two users who had problems using the Head set:

\begin{tabular}{|l|c|c|}
\hline & U6 & U2 \\
\hline Session length (minutes) & 2,43 & 4,34 \\
\hline Task (seconds) & 48,68 & 28,83 \\
\hline Mission (seconds) & 73,03 & 32,95 \\
\hline Number of missions & 3 & 8 \\
\hline Number of Tasks & 2 & 7 \\
\hline
\end{tabular}

User 6 was uncomfortable and refused to wear the head set.

User 2 had sickness on one session only so her data is compromised.

Taking data from U2 and U6 away, the results are the following:

\begin{tabular}{|l|c|c|}
\hline & Min & Max \\
\hline Session length (minutes) & 2,44 & 10,11 \\
\hline Task (seconds) & 12,21 & 25,27 \\
\hline Mission (seconds) & 14,65 & 31,92 \\
\hline Number of missions & 12 & 24 \\
\hline Number of Tasks & 10 & 19 \\
\hline
\end{tabular}

Figure 3. Data from the first tests of the Serious Games.

\section{Conclusions}

Smart Angel is a project co-funded by the Liguria Region with the aim of providing a cloud mobile platform to support urban mobility for people with mild intellectual disabilities. Within the frame of the Smart Angel project, three Serious Games have been developed in an immersive virtual reality environment supporting the development of basic skills needed for personal mobility. A cloud-mobile platform has also been developed oriented at supporting and enhancing people's autonomy, in particular with respect to their mobility in urban environments and time management.

Smart Angel has been presented as a tool for empowerment and it actually affects it at different levels:

- At the individual level, by enhancing the personal abilities of the single user.

- At group level, by equipping the tutors and their organizations with a tool that maximizes effectiveness in the delivery of their services aimed at the independent living of their users.

- At community level, by allowing more independence of the final users and therefore supporting their social life, interactions and participation.

Moving independently makes it possible to have a job, to meet friends, to do leisure time activities, and also to participate to social life and therefore become an active member of the community. Health professionals, on the other hand, having a big mass of data available on the cloud system, have the possibility to study the specific issues linked to the disability and therefore organize specific actions in order to be able to offer a better support. 
The Smart Angel platform is a concrete instance of how cutting-edge ICT technologies can act as assistive technologies to increment personal and social empowerment in people who, due to their intellectual disabilities, are at risk of exclusion. Having the possibility to gain more experience and skills automatically reflects on a better control over one's own life, and enables social participation and involvement.

\section{Acknowledgments}

The authors would like to thank all the partners of the Smart Angel project that have made the present work possible, in particular Fondazione CEPIM, for the invaluable contribution in allowing the close contact and cooperative interaction with the tutors and the target users.

\section{Author Contributions}

Laura Freina has written the paper. In the Smart Angel project, she has coordinated the user requirement collection and analysis and developed one of the three Serious Games.

Rosa Bottino and Michela Ott (scientific responsible of the project) have checked the scientific soundness of the paper, validating and enriching all the scientific reference.

Filippo Costa, as the coordinator of the Smart Angel project, has contributed by checking the present paper and verifying that what has been written actually matches with the developed prototype, which is now under test.

\section{Conflicts of Interest}

The authors declare no conflict of interest.

\section{References}

1. Page, C.E.; Czuba, N. Empowerment: What is it? J. Ext. 1999, 37, 1-5.

2. Lord, J.; Hutchison, P. The Process of Empowerment: Implications for Theory and Practice. Can. J. Community Ment. Heal. 1993, 12, 5-22.

3. Rappaport, J. Terms of empowerment/exemplars of prevention: Toward a theory for community psychology. Am. J. Community Psychol. 1987, 15, 121-148.

4. Maton, K.I.; Salem, D.A. Organizational characteristics of empowering community settings: A multiple case study approach. Am. J. Community Psychol. 1995, 23, 631-656.

5. Cyril, S.; Smith, B.J.; Renzaho, A.M.N. Systematic review of empowerment measures in health promotion. Health Promot. Int. 2015, doi:10.1093/heapro/dav059.

6. Bleumers, L.; All, A.; Mariën, I.; Schurmans, D. State of Play of Digital Games for Empowerment and Inclusion: A review of the Literature and Empirical Cases; Publication Office of the European Union: Luxembourg, Luxembourg, 2012.

7. Zimmerman, M.A. Psychological Empowerment: Issue and Illustrations. Am. J. Community Psychol. 1995, 5, 581-599.

8. Zimmerman, M. Empowerment theory. In Handbook of Community Psychology; Rappaport, J., Seidman, E., Eds.; Springer: Boston, MA, USA, 2000; pp. 43-63. 
9. Wilson, P.A. Empowerment: Community Economic Development from the Inside Out. Urban. Stud. 1996, 33, 617-630.

10. Laverack, G. Improving health outcomes through community empowerment: A review of the literature. J. Heal. Popul. Nutr. 2006, 24, 113-120.

11. Chadwick, D.; Wesson, C.; Fullwood, C. Internet Access by People with Intellectual Disabilities: Inequalities and Opportunities. Future Internet 2013, 5, 376-397.

12. Bottino, R.M. Evoluzione e Prospettive nella Ricerca in Tecnologie Didattiche. In La Didattica nell'Era Digitale; Campione, V., Ed.; Il Mulino: Bologna, Italy, 2015; pp. 23-38.

13. UniSchooLabs. Available online: http://unischoolabs.eun.org (accessed on 20 August 2015).

14. Smart Angel. Available online: www.smartangel.it (accessed on 1 July 2015).

15. Recall Project. Available online: http://www.ntu.ac.uk/apps/research/groups/9/home.aspx/project /149604/overview/recall/ (accessed on 20 August 2015).

16. AIPD L'Aquila. Progetto Casa Più. Available online: http://aipd.csvaq.it/wp-content/uploads/ 2013/01/casa-pi\%C3\%B9-opuscolo_def.pdf (accessed on 12 November 2015).

17. Pozzi, F.; Antonaci, A.; Dagnino, F.M.; Ott, M.; Tavella, M. A Participatory Approach to Define User Requirements of a Platform for Intangible Cultural Heritage Education; Istituto Tecnologie Didattiche: Genoa, Italy, 2012.

18. Freina, L.; Busi, M.; Canessa, A.; Caponetto, I.; Ott, M. Learning to Cope With Street Dangers: An Interactive Environment for Intellectually Impaired. In Proceedings of the 6th International Conference on Education and New Learning Technologies, Barcelona, Spain, 7-9 July 2014.

19. Bottino, R.M.; Canessa, A.; Ott, M.; Tavella, M. SMART VIEW: A serious game supporting spatial orientation of subjects with cognitive impairments. In Universal Access in Human-Computer Interaction. Universal Access to Information and Knowledge; Springer International Publishing: Cham (ZG), Switzerland, 2014; Volume 8514, pp. 489-500.

20. Freina, A.; Canessa, L. Immersive vs. Desktop Virtual Reality in Game Based Learning. In Proceedings of the 9th European Conference on Games Based Learning, Steinkjer, Norway, 8-9 October 2015.

21. Rose, F.D.; Attree, E.A.; Brooks, B.M.; Parslow, D.M.; Penn, P.R.; Ambihaipahan, N. Training in virtual environments: Transfer to real world tasks and equivalence to real task training. Ergonomics 2000, 43, 494-511.

22. Mell, P.; Grance, T. The NIST Definition of Cloud Computing Recommendations of the National Institute of Standards and Technology; National Institute of Standards and Technology (NIST) Special Publication: Gaithersburg, MD, USA, 2011; pp. 145-800.

23. Freina, L.; Caponetto, I. A Mobile Guardian Angel Supporting Urban Mobility for People with Dementia : An Errorless Learning Based Approach. In Proceedings of the International Conference on ICT for Ageing Well and e-Health, Lisbon, Portugal, 20-22 May 2015; pp. 307-312.

(C) 2015 by the authors; licensee MDPI, Basel, Switzerland. This article is an open access article distributed under the terms and conditions of the Creative Commons Attribution license (http://creativecommons.org/licenses/by/4.0/). 